Session 2525

\title{
Hands-on Design and Manufacturing in an Undergraduate Fluid Mechanics Course
}

\author{
Joseph J. Orlins, Eric Constans \\ Civil and Environmental Engineering / Mechanical Engineering \\ Rowan University, Glassboro, New Jersey
}

\begin{abstract}
This paper presents an effort to combine design and direct application of fundamental principles in a basic fluid mechanics course. Civil Engineering students designed and manufactured pumps, then tested them to investigate head-discharge relationships.

In this project, students in a junior-level introductory fluid mechanics class worked in teams to design and build simple reciprocating piston pumps. The project was assigned in the middle of a 15-week semester, and spanned a period of about five weeks. Students had to determine pump discharge as a function of piston size, stroke length, and speed of operation. Based upon specific design constraints, students had to select a particular motor to use with their pump. Students then worked in the machine shop, fabricating the pumps from stock materials. Completed pumps were then tested in a competition between teams to determine maximum discharge and pressure head.

This project enabled students to apply basic fluid mechanics principles early on in their fluidsrelated coursework by designing and building working pumps. The early exposure to all elements of design, testing, and evaluation aided student understanding of the basic concepts of fluid mechanics, and familiarized students with design and fabrication techniques.

\section{Introduction}

In many traditional introductory courses in Fluid Mechanics, students do not gain a true appreciation for the real-world applications where the concepts presented in the classroom are brought to life. Laboratory experiments are used to demonstrate basic principles, but usually follow a very limited and proscribed scope and format. Such labs are generally focused on investigations of fluid properties and the conservation of mass, momentum, and energy. True applications of the basic principles (such as selection of pumps and system head-discharge curves) are generally covered at the end of an introductory course, or even relegated to a second course in fluid mechanics.
\end{abstract}


In addition to the lack of true application of basic principles, students in such courses usually do not have a great deal of design experience at that stage in their curriculum. Civil engineering students in particular have a more limited appreciation for the elements of mechanical design and fabrication. The conventional wisdom is that "CE students don't need to know how to make mechanical things; they just need to specify what will be used." In other words, civil engineers are taught to look in a catalog to find a suitable device (such as a pump) for a particular application. The principles of turbomachinery are often a part of undergraduate civil engineering curricula, but the theoretical approach of most textbooks still does not provide a deep understanding of the nature of machines required to perform a specific task. Not only do students fail to understand the mechanical aspects of devices such as pumps, they often lack the insight as to what can and cannot be physically built in a machine shop.

To address these problems, a cross-curricular project similar to that used by Constans and Gabler $^{1,2}$ was used. Constans and Gabler coupled thermodynamics and mechanical design for junior-level Mechanical Engineering students with a project to build air compressors. A simple reciprocating piston compressor is essentially a positive displacement pump, with the fluid of concern a gas of some sort. Since Civil Engineering students typically deal with incompressible fluids (e.g. water), the concept of a piston pump was developed. The pump project undertaken during the Fall Semester 2000 Fluid Mechanics course had the following educational goals:

\section{Fluid Mechanics}

(a) Introduction to turbomachinery

(b) Control volumes, application of continuity

(c) Head-discharge relationships for positive displacement pumps

Mechanical Design

(d) Design of a linkage to perform a specific task

Prototyping Skills

(e) Transfer of theoretical design into physical design

(f) Fabrication of pump parts in the Rowan Machine Shop

(g) Design testing / evaluation / improvement

\section{Design Assignment}

In the middle of the semester, students started on the design and fabrication of their pumps. The first part of the design was an individual homework assignment. Students had to calculate and plot discharge for a single-acting reciprocating piston pump as a function of cylinder diameter (D), piston stroke length (L), and motor speed (N), for a variety of diameters, stroke lengths, and motor speeds. A definition sketch (Figure 1) was provided to the students. The instructor reviewed all of the individual assignments, to ensure that students understood the basic concepts involved in operation of positive displacement pumps. 


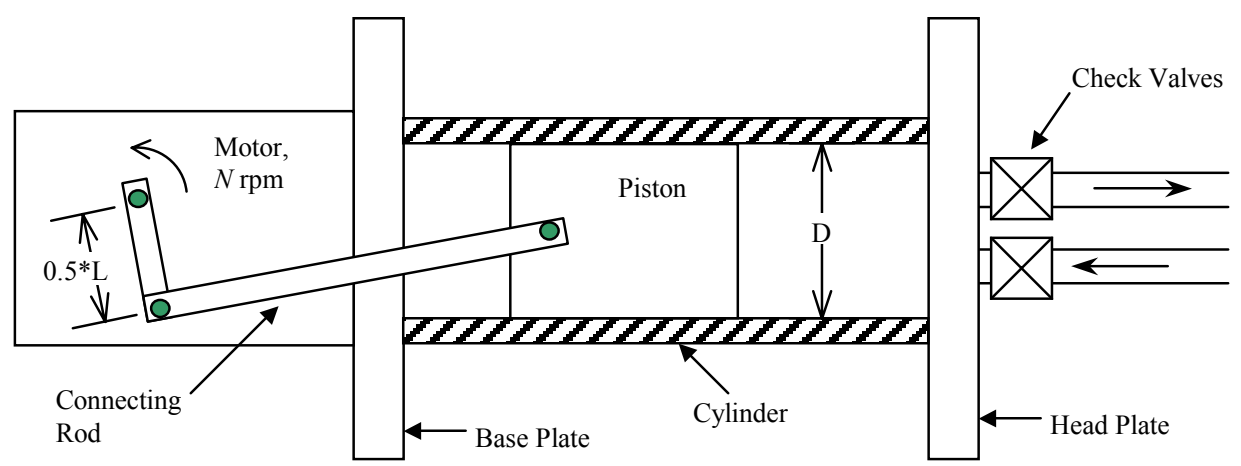

Figure 1: Nomenclature and definition sketch for pump

The remainder of the project was done with students working in teams of four. Each group had to select an electric motor \& gearbox, to build a pump to deliver 1 liter per minute of water, with a cylinder diameter of $3.8 \mathrm{~cm}$. To use a standard gearbox (i.e., motor rotational speed), each team had to determine the appropriate stroke length, L, to achieve the target flow rate. In addition, consideration had to be given to the maximum and running torque provided by the motor.

\section{Fabrication}

Materials for the fabrication of the pumps were provided to the students. These included clear acrylic tubing for the cylinder, head plate, and motor base plate, the motor and gearbox selected by each team, and all required hardware and electrical connections.

Fabrication was done in the project lab / machine shop in the campus engineering building, during four regularly scheduled lab periods. Students worked under the supervision of the course instructor (Orlins, Civil Engineering), a Mechanical Engineering faculty member (Constans), and machine shop staff. Since one of the objectives of the project was to give students experience fabricating a machine from scratch, faculty acted merely as observers and instructors, in a 'handsoff' capacity. All students participated in the fabrication of the pumps, as shown in Figures 2 through 5.

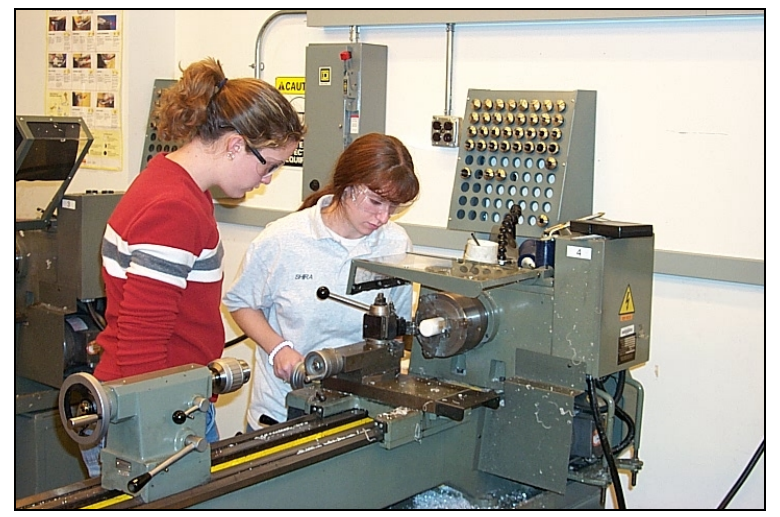

Figure 2: Turning o-ring grooves on a piston.

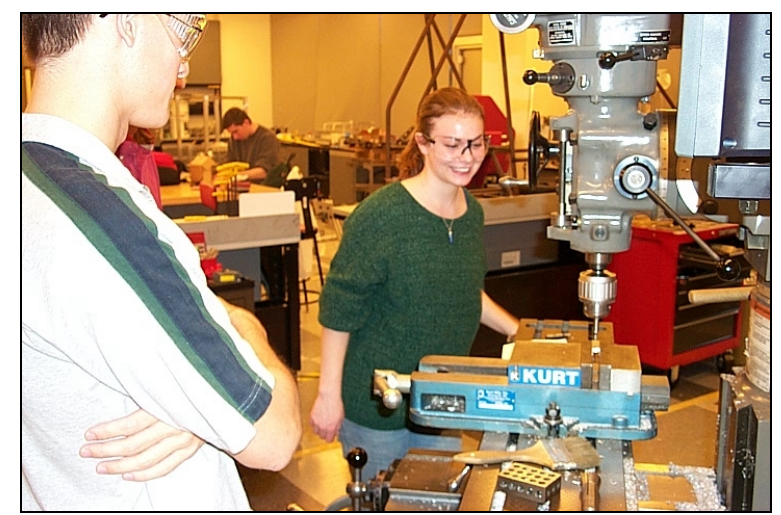

Figure 3: Fabricating connecting rod with milling machine.

Proceedings of the 2001 American Society for Engineering Education Annual Conference \& Exposition Copyright (C) 2001, American Society for Engineering Education 


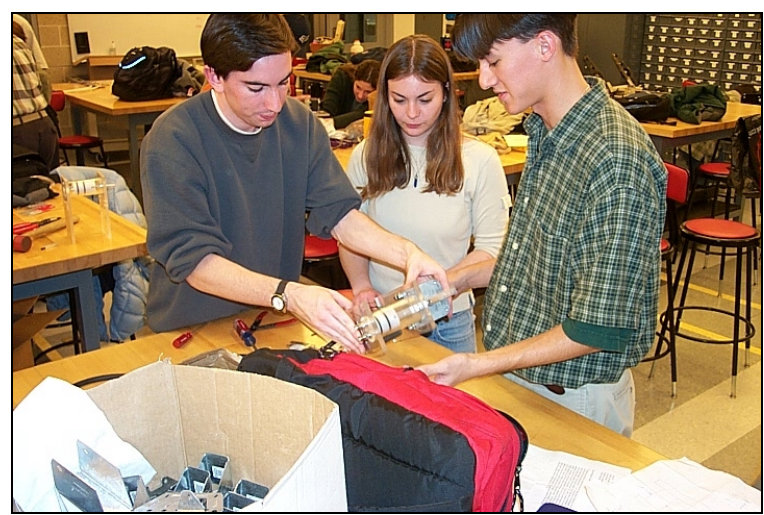

Figure 4: Fitting piston in cylinder.

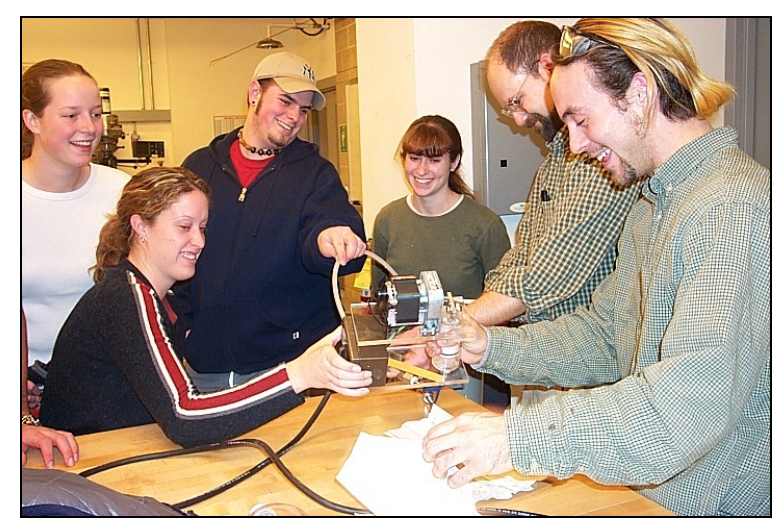

Figure 5: First test of completed pump.

There were a number of challenges facing both the students and instructors, ranging from material procurement to different student experience levels. By far the most challenging of these was the students' inexperience in prototype fabrication using machine tools. During the course of the project, students were taught enough machining skills (milling, turning, etc.) to build their prototypes, while simultaneously learning the engineering skills needed to develop and refine their designs.

\section{Evaluation}

The students' devices were evaluated in a 'Pump Fest,' held in the Atrium of the engineering building on the last day of class. There were three categories of competition: Closest to Design Discharge, Maximum Discharge, and Head Produced. Discharge was measured by the time required to fill a 1-liter graduated cylinder. Head was measured using a pressure gage and standpipe. The standpipe was run from the ground level of the building to the $3^{\text {rd }}$ floor, so students could visualize the head produced by each pump. Student activities during the "Pump Fest" are shown in Figures 6 to 9. The authors found that the competition between the teams increased student enthusiasm and improved the overall quality of the designs and prototypes.

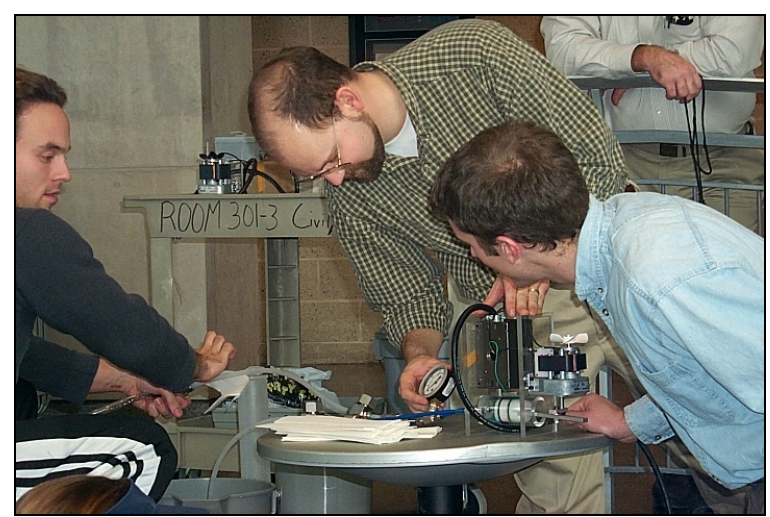

Figure 6: The authors inspecting a pump entry.

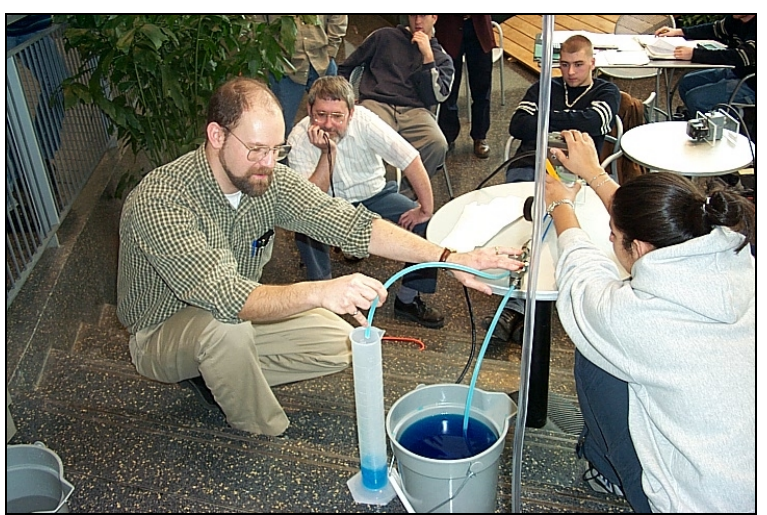

Figure 7: Measuring pump discharge.

Proceedings of the 2001 American Society for Engineering Education Annual Conference \& Exposition Copyright (C) 2001, American Society for Engineering Education 


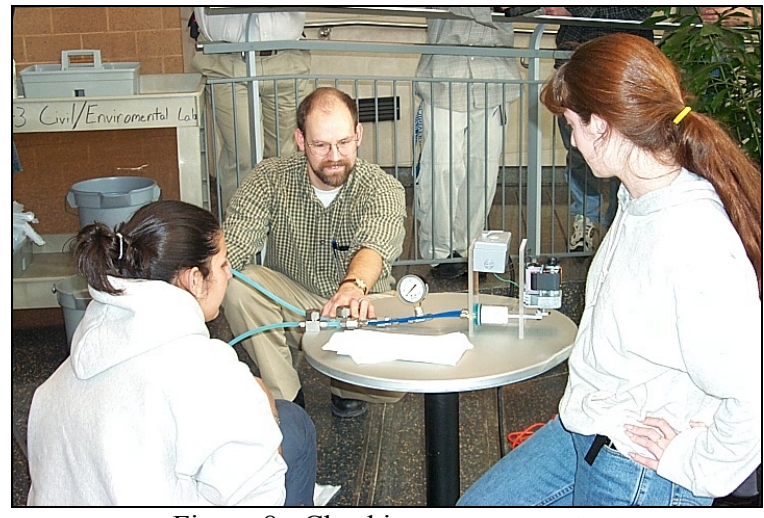

Figure 8: Checking pressure output.

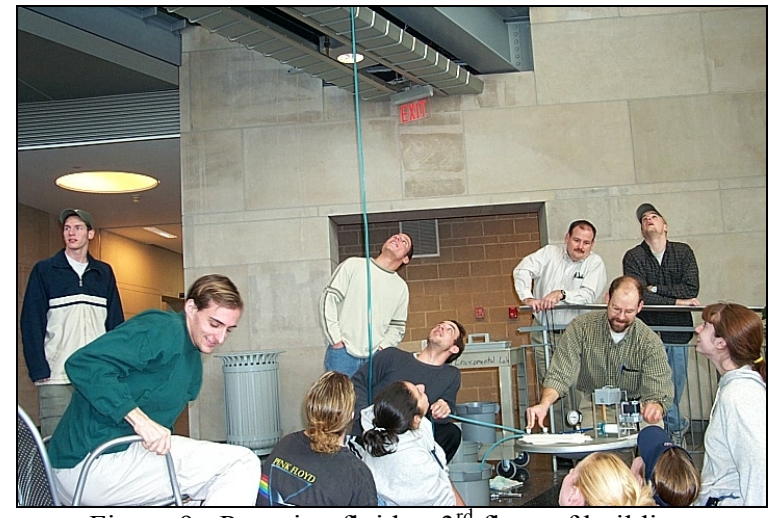

Figure 9: Pumping fluid to $3^{\text {rd }}$ floor of building.

\section{Documentation}

Each project team had to submit a brief write-up of the project, including a complete set of design drawings for their pump. The short report included a bill of all materials needed to fabricate the pump, a summary of the pump design and performance, and recommendations for improvements to the design. Figure 10 shows a typical design assembly drawing submitted by one student team at the end of the project.

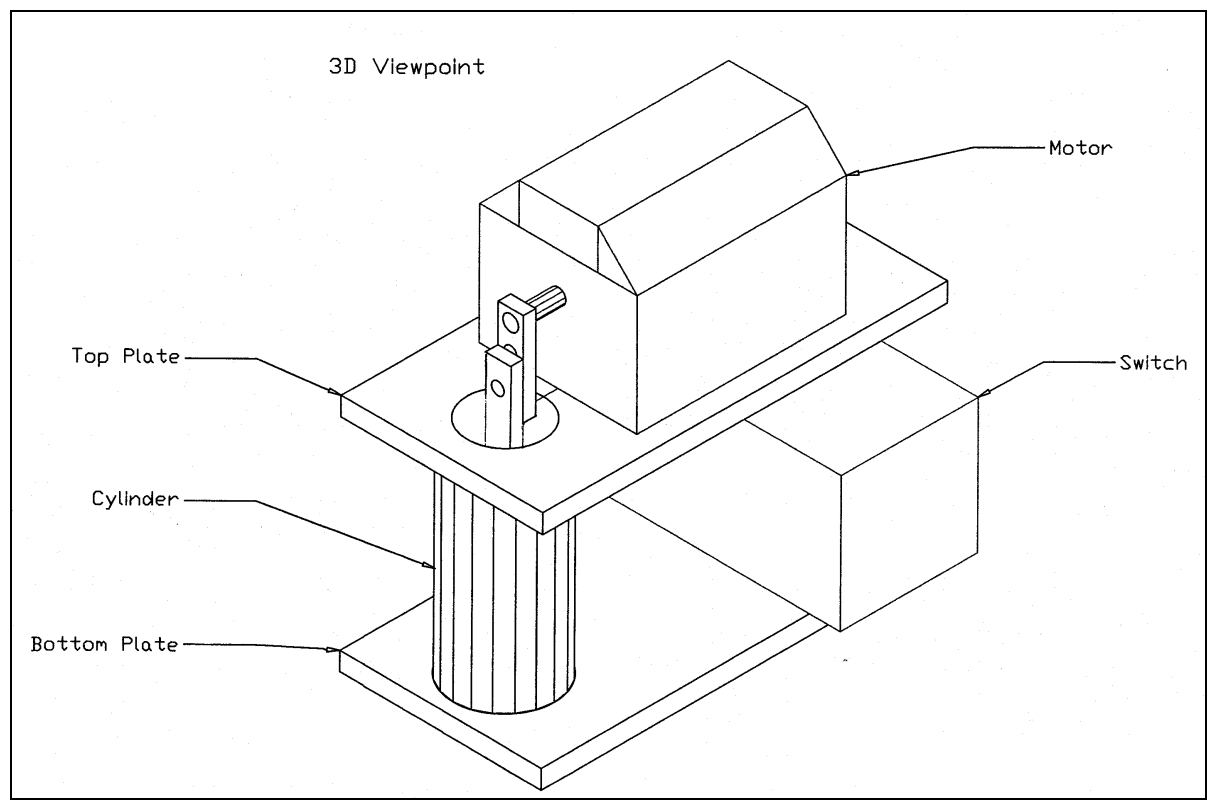

Figure 10: CAD assembly drawing submitted by student team. 


\section{Conclusions}

The pump design and fabrication project undertaken in a basic Civil Engineering class in Fluid Mechanics was a success. Students gained an understanding of turbomachinery, mechanical design, and prototype fabrication. Based upon an end-of-course survey, 17/19 students felt the project was a useful addition to the course. One student commented "it caused us [the class] to see the concepts in physical form." However, not all students were positive about the experience. One student commented that the project was "only useful because it was conducted during class time," and number of students felt that more course time could have been spent on traditional lab exercises. Despite these few negative comments, overall class reaction was encouraging and positive.

In the future, the project will be started earlier in the semester, and fewer lab sessions will be devoted to pump fabrication in the machine shop. Since the shop facilities in our College of Engineering are open to all students during normal business hours, students will be required to work on the project outside of normal class time.

This hands-on project enabled traditional Civil Engineering students to more fully understand the process of design and fabrication of the types of pumping machinery they will use in their professional careers.

Bibliography

1. Constans, E.W., and Gabler, H.C, 2000. Coupling thermodynamics and mechanical design in a cross-curricular undergraduate design project, ASEE/IEEE Frontiers in Engineering Education 2000, Kansas City, MO, T1F-10 - T1F-12.

2. Constans, E.W., and Gabler, H.C., 2000. The compressor project: coupling thermodynamics and mechanical design in a cross-curricular project, American Society for Engineering Education Mid-Atlantic Regional Conference, 143-149.

\section{JOSEPH ORLINS}

Joseph Orlins is an Assistant Professor of Civil and Environmental Engineering in the College of Engineering at Rowan University. Dr. Orlins is a registered Professional Civil Engineer in Washington and Minnesota and is actively involved in water resources engineering education and research. Dr. Orlins received his B.S.C.E. degree from the University of Washington in 1993, and his M.S. and Ph.D. degrees in Civil Engineering at the University of Minnesota in 1996 and 1999, respectively.

\section{ERIC CONSTANS}

Eric Constans is an Assistant Professor of Mechanical Engineering in the College of Engineering at Rowan University. Dr. Constans is also actively involved in engineering education and research. His research interests finite elements, optimization, and acoustics. Prior to joining the faculty at Rowan, Dr. Constans worked as an acoustician for Continental Tire Company, in Hannover, Germany. Dr. Constans received his B.S. degree from the University of Washington in 1992, and his M.S. and Ph.D. degrees in Mechanical Engineering at the Penn State University in 1994 and 1997, respectively. 